\title{
Thyroid Abnormalities in Survivors of Childhood Cancer
}

\author{
Ayla Akca Çağlar1, Aynur Oğuz2, Faruk Güçlü Pınarlı2, Ceyda Karadeniz2, Arzu Okur2, Aysun Bideci3, \\ Ülker Koçak4, Hüseyin Bora5 \\ ${ }^{1}$ Gazi University, Faculty of Medicine, Pediatrics, Ankara, Turkey \\ 2 Gazi University, Faculty of Medicine, Pediatric Oncology, Ankara, Turkey \\ 3 Gazi University, Faculty of Medicine, Pediatric Endocrinology, Ankara, Turkey \\ ${ }^{4}$ Gazi University, Faculty of Medicine, Pediatric Hematology, Ankara, Turkey \\ 5 Gazi University, Faculty of Medicine, Radiation Oncology, Ankara, Turkey
}

\section{ABSTRACT}

Objective: To investigate the late side effects of childhood cancer therapy on the thyroid gland and to determine the risk factors for development of thyroid disorder among childhood cancer survivors.

Methods: One hundred and twenty relapse-free survivors of childhood cancer (aged 6-30 years) were included in this study. The diagnoses of patients were lymphoma, leukemia, brain tumor, rhabdomyosarcoma and nasopharyngeal carcinoma (NPC). The patients were divided into two groups depending on the treatment: group 1-chemotherapy (ChT) only $(\mathrm{n}=52)$ and group 2-combination therapy of $\mathrm{ChT}+$ radiotherapy (RT) (head/ neck/thorax) ( $\mathrm{n}=68$ ). Thyroid function tests, urinary iodine levels, and thyroid gland ultrasound examinations were evaluated in both groups.

Results: Incidence of thyroid disease was $66 \%(n=79)$ in the survivors The thyroid abnormalities were: hypothyroidism (HT) ( $n=32,27 \%)$, thyroid nodules $(n=27,22 \%)$, thyroid parenchymal heterogeneity $(n=40,33 \%)$ autoimmune thyroiditis $(n=36,30 \%)$, and thyroid malignancy $(n=3,2 \%)$. While the incidence of HT and thyroid nodules in group 2 was significantly higher than in group 1, the incidence of thyroid parenchymal heterogeneity and autoimmune thyroiditis was similar in the two patient groups. HT and thyroid malignancy were seen only in group 2. In multivariate logistic regression analysis, a history of Hodgkin lymphoma (HL), brain tumor and NPC, as well as cervical irradiation and 5000-5999 cGy doses of radiation were found to constitute risk factors for HT. History of HL and 4000-5999 cGy doses of radiation were risk factors for thyroid nodules. Head/neck irradiation and treatment with platinum derivatives were risk factors for autoimmune thyroiditis. In univariate analysis, a history of NPC, cervical + nasopharyngeal irradiation, and treatment with platinum derivatives were risk factors for thyroid parenchymal heterogeneity.

Conclusion: Our results indicate that there is especially an increased risk of $\mathrm{HT}$ and thyroid nodules in patients treated with combination therapy of

\section{Introduction}

Improvement in treatment of childhood malignancies has led to a decrease in mortality, and the overall 5-year survival rate for childhood cancers is now around $80 \%$ (1). This decrease has also led to a change in the scope of research, which at present focuses on detection of long-term side effects of treatment modalities.

Endocrine disorders are the most common long-term complication of cancer therapy. The side effects of this therapy on the endocrine system involve the hypothalamo-pituitary axis, the thyroid gland and the gonads (2). Thyroid dysfunction has been reported especially following head and neck irradiation $(3,4,5)$. Although primary subclinical (compensated) hypothyroidism $(\mathrm{HT})$ is the most common complication of this therapy, overt HT, Graves' disease, benign nodules and thyroid malignancies can also occur after cervical radiotherapy (RT) $(6,7,8)$. While the risk of thyroid dysfunction following RT has been described, the effect of chemotherapeutic agents on the thyroid gland has not yet been as well characterized.

In this study, our aim was to investigate the late side effects of childhood cancer therapy on the thyroid gland and to determine the risk factors for development of thyroid disorder among childhood cancer survivors.

\section{Methods}

The study included 120 relapse-free survivors of childhood cancer (84 male, 36 female, aged 6-30 years) who have been

\footnotetext{
Address for Correspondence

Ayla Akca Çağlar MD, Gazi University, Faculty of Medicine, Pediatrics, Ankara, Turkey Gsm: +905055625826 E-mail: dr.aylaakca@hotmail.com

OJournal of Clinical Research in Pediatric Endocrinology, Published by Galenos Publishing.
} 
ChT with head/neck/thorax RT. Although chemotherapeutic agents per se do not seem to cause HT, longer follow-up is needed to assess whether or not there is an increased risk for autoimmune thyroiditis and thyroid parenchymal heterogeneity after antineoplastic therapy.

Key words: Childhood cancer survivors, chemotherapy, radiotherapy, late effects, thyroid

Conflict of interest: None declared

Received: 23.02.2014

Accepted: 30.04 .2014

followed between November 1992 and October 2010 in the Department of Pediatric Hematology and Oncology at Gazi University Medical Faculty in Ankara, Turkey. The patients were divided into two groups depending on the type of treatment: Group 1-chemotherapy (ChT) only and Group 2-combination therapy of ChT with RT (head/neck/thorax). Group 1 consisted of 52 patients with diagnoses of non-Hodgkin lymphoma (NHL; $n=27)$, leukemia $(n=23)$ and $H L(n=2)$. Group 2 consisted of 68 patients with diagnoses of $H L(n=41)$, brain tumor $(n=7)$, rhabdomyosarcoma (RMS; $n=6)$, nasopharyngeal carcinoma (NPC; $n=6)$, leukemia $(n=5), N H L(n=2)$, retinoblastoma $(n=1)$ and pleuropulmonary blastoma $(n=1)$. Informed consent was obtained from all patients or parents. The research protocol was approved by the medical ethics committee.

Thyroid function studies including thyroid-stimulating hormone (TSH), plasma total thyroxine (tT4), free T4 (fT4), thyroglobulin (TG), thyroid antibodies (AB) [anti-thyroglobulin (antiTG) and anti-thyroid peroxidase (anti-TPO)] and urinary iodine levels were measured in all patients. Normal values for these parameters were: TSH: 0.55-4.78 $\mu \mathrm{U} / \mathrm{L}$, tT4: 4.87-11.72 $\mu \mathrm{g} / \mathrm{dL}$, fT4: 0.74-1.52 $\mu \mathrm{g} / \mathrm{dL}, \mathrm{Tg}: 1.6-59.9 \mathrm{ng} / \mathrm{mL}$, anti-TPO: 0-57 U/mL and anti-Tg: 0-64 U/mL. Plasma TSH, fT4, tT4 and AB levels were measured by chemiluminescence immunoassay (Siemens Immulite 2000). Tg was also determined by chemiluminescence immunoassay (Siemens-Centaur). Primary overt HT was defined as a low fT4 level and an elevated TSH. Compensated HT was defined as a high TSH level with a normal fT4 value. Central HT was diagnosed when accompanied by a low serum $\mathrm{T} 4$ with low or normal TSH levels. The presence of AB was accepted to indicate autoimmune thyroiditis. Urinary iodine levels were measured by spectrophotometry and levels $\geq 10 \mu \mathrm{g} / \mathrm{dL}$ were accepted as normal. Severe iodine deficiency was defined as urinary iodine levels lower than $2 \mu \mathrm{g} / \mathrm{dL}$. Moderate iodine deficiency was defined as a urinary iodine level between 2 and $4.9 \mu \mathrm{g} / \mathrm{dL}$ and mild iodine deficiency as $5-9.9 \mu \mathrm{g} / \mathrm{dL}$. Thyroid gland ultrasound was also performed (Hitachi EVB-7500 HV) for the diagnosis of thyroid nodules and thyroid parenchymal heterogeneity.

Eligibility criteria for inclusion in the current analysis were: diagnosis of the cancer at age $\leq 18$ years, treatment with $\mathrm{ChT}$ only or both $\mathrm{ChT}$ and RT (head/neck/thorax) and a time interval of $\geq 6$ months after completion of the therapy. Exclusion criteria for the analysis were history of thyroid disorder prior to the cancer therapy, severe iodine deficiency, treatment with RT only and RT treatment in field outside the thyroid area.

\section{Statistics}

Statistical analyses were performed using SPSS 15.0. Numerical data are expressed as median, minimum and maximum. All results are given as frequencies. The student's t-test was used for comparison of quantitative data and chisquare for qualitative data. Univariate analyses of the patient and treatment factors possibly associated with thyroid disease were performed using the logistic regression to derive the odds ratios and their chi-square p-values. Covariates were included in a multivariate analysis if they turned out to have $p<0.05$ in the univariate assessments. The time elapsed after diagnosis of primary cancer and development of events was estimated using the method of Kaplan and Meir (9). All statistical tests were two-tailed and statistical significance was considered when the p-value was less than 0.05 .

\section{Results}

Patient characteristics are shown in (Table 1). Mean age at diagnosis of malignancy was 8.5 years (1-17 years), mean current age was 16.4 years (6-30 years) and mean time elapsed after completion of the therapy was 7.8 years $(0.75-18$ years).

Overall, 79 (66\%) survivors had developed thyroid disease. Thyroid abnormalities were HT $(n=32,27 \%)$, thyroid nodules $(n=27,22 \%)$, thyroid parenchymal heterogeneity $(n=40,33 \%)$, autoimmune thyroiditis $(n=36,30 \%)$ and thyroid malignancy $(n=3,2 \%)$ (Table 2). Severe iodine deficiency was not detected in any patient. Four patients had moderate and 24 patients had mild iodine deficiency.

Primary HT was seen in 31 (26\%) patients (27 compensated and 4 overt HT), whereas central HT was diagnosed in only 1 case $(0.8 \%)$ with brain tumor. HT was found only in Group 2 patients $(p=0.000$ ) (Table 2). The median time to development of HT was 5 years $(0.5-12.5$ years).

Sonographic abnormalities of the thyroid were found in 54 (45\%) patients and 27 (22\%) patients had thyroid nodules (solitary nodules in 14 patients and multiple-in 13 patients). Among the patients with thyroid nodules detected by ultrasonography, 3 had thyroid malignancy with a median duration of 11.5 years after the therapy. The median time to presence of thyroid nodules was 9 years (1-17 years) after cessation of the therapy. Thyroid nodules were more common in Group 2 ( $p=0.000$ ) (Table 2).

Frequency rates of HT and thyroid nodules and significant variables associated with $\mathrm{HT}$ and thyroid nodules in univariate logistic regression analysis are shown in (Table 3).

Vinca alkaloids and alkylating agents were the most commonly used drugs in the survivors (in 97\% and 92\%, respectively), followed by corticosteroids (88\%), antineoplastic antibiotics (85\%), antimetabolites (54\%), intrathecal therapy $(50 \%)$, asparaginase $(27 \%)$, platinum derivatives $(7 \%)$ and others 


\begin{tabular}{|c|c|c|c|c|}
\hline & $\begin{array}{l}\text { Total } \\
(n=120, \%)\end{array}$ & $\begin{array}{l}\text { Group } 1 \\
(\mathrm{n}=52, \%)\end{array}$ & $\begin{array}{l}\text { Group 2 } \\
(\mathrm{n}=68, \%)\end{array}$ & p-value \\
\hline Sex & & & & 0.688 \\
\hline Male, $\mathrm{n}(\%)$ & $84(70)$ & $35(67)$ & 49 (72) & \\
\hline Female, $n(\%)$ & $36(30)$ & $17(33)$ & $19(28)$ & \\
\hline Age at diagnosis of malignancy (yrs), (mean $\pm S D$ ) & $8.5 \pm 3.8$ & $8.5 \pm 4.3$ & $8.5 \pm 3.4$ & 0.963 \\
\hline Current age (yrs), (mean $\pm S D)$ & $16.4 \pm 5.5$ & $15.4 \pm 6.0$ & $17.1 \pm 5.1$ & 0.118 \\
\hline Time elapsed after completion of therapy (yrs), (mean \pm SD) & $7.8 \pm 5.2$ & $6.9 \pm 4.6$ & $8.5 \pm 5.5$ & 0.099 \\
\hline \multicolumn{5}{|l|}{ Diagnosis } \\
\hline $\mathrm{HL}$ & $43(36)$ & $2(4)$ & $41(60)$ & \\
\hline NHL & $29(24)$ & 27 (52) & $2(3)$ & \\
\hline Leukemia & $28(23)$ & $23(44)$ & $5(7)$ & \\
\hline Brain tumor & $7(6)$ & 0 & $7(10)$ & \\
\hline RMS & $6(5)$ & 0 & $6(9)$ & \\
\hline NPC & $5(4)$ & 0 & $5(7)$ & \\
\hline Others & $2(2)$ & 0 & $2(3)$ & \\
\hline
\end{tabular}

Table 2. Occurrence of thyroid disease in each patient group

\begin{tabular}{|c|c|c|c|c|}
\hline Thyroid disease & Group $1(n=52, \%)$ & Group $2(n=68, \%)$ & All $(n=120, \%)$ & p-value \\
\hline HT & 0 & $32(47)$ & $32(27)$ & $0.000^{\mathrm{a}}$ \\
\hline Sonographic abnormalities & $16(31)$ & $38(56)$ & $54(45)$ & $0.009^{a}$ \\
\hline Nodules & $2(4)$ & $25(37)$ & $27(22)$ & $0.000^{\mathrm{a}}$ \\
\hline Parenchymal heterogeneity & $14(27)$ & $26(38)$ & $40(33)$ & 0.242 \\
\hline Autoimmune thyroiditis & $16(31)$ & $20(29)$ & $36(30)$ & 1.000 \\
\hline Thyroid malignancy & 0 & $3(4)$ & $3(2)$ & \\
\hline All & $26(50)$ & $53(78)$ & $79(66)$ & $0.002^{\mathrm{a}}$ \\
\hline \multicolumn{5}{|l|}{$\begin{array}{l}{ }^{a} \mathrm{p} \text {-value significant when }<0.05 \\
\mathrm{HT} \text { : hypothyroidism } \\
\text { Note: Many patients had more than one abnormality }\end{array}$} \\
\hline
\end{tabular}

(9\%). Treatment with any type of chemotherapeutic agents did not increase the risk for developing $\mathrm{HT}$ and thyroid nodules. Also, patients with a history of NHL and leukemia, treatment with antineoplastic antibiotics, antimetabolites, asparaginase and intrathecal therapy were less prone to develop HT and thyroid nodules (Table 3).

Incidence of thyroid parenchymal heterogeneity and autoimmune thyroiditis was similar in Group 1 and Group 2 (Table 2). Frequency rates of thyroid parenchymal heterogeneity and autoimmune thyroiditis and significant variables associated with thyroid parenchymal heterogeneity and autoimmune thyroiditis in univariate logistic regression analysis are shown in (Table 4).
The results of multivariate logistic regression analysis of the significant variables associated with $\mathrm{HT}$, thyroid nodules and autoimmune thyroiditis are shown in (Table 5). There was no significant variable associated with parenchymal heterogeneity in the multivariate logistic regression analysis.

\section{Discussion}

In our patient groups, $27 \%$ of the patients had HT, similar to the incidence reported by Madanat et al (10) and Van Santen et al (11). In line with several studies which have documented a higher incidence for subclinical HT as compared to overt HT $(12,13,14)$, we also observed a higher rate of subclinical HT. 
Akca Çağlar A et al.

Thyroid Abnormalities in Children with Cancer

Table 3. Univariate analysis of risk factors for developing hypothyroidism and thyroid nodules

\begin{tabular}{|c|c|c|c|c|c|c|c|c|}
\hline & \multicolumn{4}{|c|}{ Hypothyroidism } & \multicolumn{4}{|c|}{ Thyroid nodules } \\
\hline & Frequency & OR & $95 \% \mathrm{Cl}$ & p-value & Frequency & $\mathrm{OR}$ & $95 \% \mathrm{Cl}$ & $\mathrm{p}$-value \\
\hline Female sex $(n=36)$ & $8(22 \%)$ & 0.7 & $0.2-1.7$ & 0.509 & $8(22 \%)$ & 0.9 & $0.3-2.4$ & 1.000 \\
\hline \multicolumn{9}{|l|}{ Tumor type } \\
\hline $\mathrm{HL}(\mathrm{n}=43)$ & $22(51 \%)$ & 7.0 & $2.8-17.1$ & $0.000^{\mathrm{a}}$ & $18(42 \%)$ & 5.4 & $2.1-13.6$ & $0.000^{\mathrm{a}}$ \\
\hline $\mathrm{NHL}(\mathrm{n}=29)$ & 0 & NA & NA & $0.000^{\mathrm{a}}$ & $1(3 \%)$ & 0.08 & $0.01-0.6$ & $0.004^{\mathrm{a}}$ \\
\hline Leukemia ( $\mathrm{n}=28$ ) & 0 & NA & NA & $0.000^{\mathrm{a}}$ & $1(4 \%)$ & 0.09 & $0.01-0.7$ & $0.004^{\mathrm{a}}$ \\
\hline Brain tumor $(n=7)$ & $5(71 \%)$ & 7.9 & $1.4-43.4$ & $0.014^{\mathrm{a}}$ & $3(43 \%)$ & 2.7 & $0.5-13.2$ & 0.188 \\
\hline$N P C(n=5)$ & $4(80 \%)$ & 12.4 & $1.3-115.8$ & $0.018^{\mathrm{a}}$ & $2(40 \%)$ & 2.4 & $0.3-15.1$ & 0.314 \\
\hline $\mathrm{RMS}(\mathrm{n}=6)$ & $1(17 \%)$ & 0.5 & $0.06-4.7$ & 1.000 & $1(17 \%)$ & 0.6 & $0.07-6.05$ & 1.000 \\
\hline Others $(n=2)$ & 0 & NA & NA & 1.000 & $1(50 \%)$ & 3.5 & $0.2-58.5$ & 0.401 \\
\hline \multicolumn{9}{|l|}{ RT field } \\
\hline Cervical $(n=25)$ & $16(64 \%)$ & 8.7 & $3.3-23.3$ & $0.000^{\mathrm{a}}$ & $9(36 \%)$ & 2.4 & $0.9-6.3$ & 0.104 \\
\hline Mantle $(n=4)$ & $4(100 \%)$ & NA & NA & $0.004^{\mathrm{a}}$ & $3(75 \%)$ & 11.5 & $1.1-115.5$ & $0.035^{\mathrm{a}}$ \\
\hline Cranial $(n=9)$ & $4(44 \%)$ & 2.3 & $0.5-9.4$ & 0.245 & $2(22 \%)$ & 0.9 & $0.1-5.0$ & 1.000 \\
\hline Craniospinal $(n=3)$ & $1(33 \%)$ & 1.3 & $1.1-15.8$ & 1.000 & $1(33 \%)$ & 1.7 & $0.1-20.0$ & 0.538 \\
\hline Mediastinal $(n=6)$ & 0 & NA & NA & 0.191 & $1(17 \%)$ & 0.6 & $0.07-6.0$ & 1.000 \\
\hline Cervical + Naso-pharyngeal $(n=6)$ & $4(67 \%)$ & 6.1 & $1.06-35.3$ & $0.043^{\mathrm{a}}$ & $3(50 \%)$ & 3.7 & $0.7-19.7$ & 0.127 \\
\hline Cervical + Mediastinal $(n=8)$ & $3(37 \%)$ & 1.7 & $0.3-7.6$ & 0.438 & $4(50 \%)$ & 3.8 & $0.8-16.6$ & 0.075 \\
\hline Head \& Neck $(n=7)$ & 0 & NA & NA & 0.187 & $2(29 \%)$ & 1.4 & $0.2-7.6$ & 0.654 \\
\hline \multicolumn{9}{|l|}{ Dosage of RT (cGy) } \\
\hline$<2000(n=11)$ & $5(45 \%)$ & 2.5 & $0.7-8.9$ & 0.160 & $3(27 \%)$ & 1.3 & $0.3-5.3$ & 0.709 \\
\hline $2000-2999(n=28)$ & $15(54 \%)$ & 5.0 & $2.0-12.6$ & $0.001^{\mathrm{a}}$ & $10(36 \%)$ & 2.4 & $0.9-6.2$ & 0.071 \\
\hline $3000-3999(n=5)$ & $1(20 \%)$ & 0.6 & $0.07-6.2$ & 1.000 & $1(20 \%)$ & 0.8 & $0.09-7.9$ & 1.000 \\
\hline $4000-4999(n=7)$ & 0 & NA & NA & 0.187 & $5(71 \%)$ & 10.3 & $1.8-56.8$ & $0.006^{\mathrm{a}}$ \\
\hline $5000-5999(n=7)$ & $5(71 \%)$ & 7.9 & $1.4-43.4$ & $0.014^{\mathrm{a}}$ & $4(57 \%)$ & 5.2 & $1.09-24.9$ & $0.045^{\mathrm{a}}$ \\
\hline$\geq 6000(n=10)$ & $6(60 \%)$ & 4.8 & $1.2-18.4$ & $0.022^{\mathrm{a}}$ & $2(20 \%)$ & 0.8 & $0.1-4.2$ & 1.000 \\
\hline \multicolumn{9}{|l|}{ ChT } \\
\hline Alkylating agents $(n=110)$ & $29(26 \%)$ & 0.8 & $0.2-3.4$ & 0.725 & $25(23 \%)$ & 1.1 & $0.2-5.9$ & 1.000 \\
\hline Antineoplastic anti-biotics ( $n=102$ ) & $18(18 \%)$ & 0.06 & $0.01-0.2$ & $0.000^{\mathrm{a}}$ & $18(18 \%)$ & 0.2 & $0.07-0.6$ & $0.005^{\mathrm{a}}$ \\
\hline Antimetabolites ( $n=65)$ & $4(6 \%)$ & 0.06 & $0.02-0.1$ & $0.000^{\mathrm{a}}$ & $5(8 \%)$ & 0.1 & $0.04-0.3$ & $0.000^{\mathrm{a}}$ \\
\hline Vinca alkaloids ( $n=116)$ & $29(25 \%)$ & 0.1 & $0.01-1.1$ & 0.058 & $26(22 \%)$ & 0.8 & $0.08-8.6$ & 1.000 \\
\hline Steroids ( $n=106$ ) & $25(24 \%)$ & 0.3 & $0.09-0.9$ & 0.052 & $21(20 \%)$ & 0.3 & $0.1-1.05$ & 0.083 \\
\hline Platinum derivatives $(n=9)$ & $5(56 \%)$ & 3.8 & $0.9-15.5$ & 0.056 & $3(33 \%)$ & 1.8 & $0.4-7.7$ & 0.419 \\
\hline Asparaginase $(n=32)$ & $1(3 \%)$ & 0.05 & $0.008-0.4$ & $0.000^{\mathrm{a}}$ & $1(3 \%)$ & 0.07 & $0.01-0.5$ & $0.001^{\mathrm{a}}$ \\
\hline Intrathecal therapy $(n=60)$ & $1(2 \%)$ & 0.01 & $0.002-0.1$ & $0.000^{\mathrm{a}}$ & $3(5 \%)$ & 0.07 & $0.02-0.2$ & $0.000^{\mathrm{a}}$ \\
\hline Others ( $n=11$ ) & 0 & NA & NA & $0.035^{\mathrm{a}}$ & $1(9 \%)$ & 0.3 & $0.03-2.6$ & 0.452 \\
\hline \multicolumn{9}{|c|}{$\begin{array}{l}\text { ap-value significant when < } 0.05 \\
\text { ChT: chemotherapy, RT: radiotherapy, HL: Hodgkin lymphoma, NHL: non-Hodgkin lymphoma, NPC: nasopharyngeal carcinoma, RMS: rhabdomyosarcoma, OR: odds ratio, } 95 \% \text { Cl: } 95 \% \\
\text { confidence interval, NA: not applicable }\end{array}$} \\
\hline
\end{tabular}


Akca Çağlar A et al

Thyroid Abnormalities in Children with Cancer

Table 4. Univariate analysis of risk factors for developing parenchymal heterogeneity and autoimmune thyroiditis

\begin{tabular}{|c|c|c|c|c|c|c|c|c|}
\hline & \multicolumn{4}{|c|}{ Parenchymal heterogeneity } & \multicolumn{4}{|c|}{ Autoimmune thyroiditis } \\
\hline & Frequency & $\mathrm{OR}$ & $95 \% \mathrm{Cl}$ & p-value & Frequency & OR & $95 \% \mathrm{Cl}$ & p-value \\
\hline Female sex $(n=36)$ & $12(33 \%)$ & 1.0 & $0.4-2.2$ & 1.000 & $16(44 \%)$ & 2.5 & $1.1-5.8$ & $0.030^{\mathrm{a}}$ \\
\hline \multicolumn{9}{|l|}{ Tumor type } \\
\hline$H L(n=43)$ & $13(30 \%)$ & 0.8 & $0.3-1.7$ & 0.688 & $9(21 \%)$ & 0.4 & $0.2-1.1$ & 0.146 \\
\hline $\mathrm{NHL}(\mathrm{n}=29)$ & $4(14 \%)$ & 0.2 & $0.07-0.7$ & $0.012^{\mathrm{a}}$ & $8(28 \%)$ & 0.8 & $0.3-2.1$ & 0.819 \\
\hline Leukemia ( $n=28$ ) & $12(43 \%)$ & 1.7 & $0.7-4.0$ & 0.256 & $9(32 \%)$ & 1.1 & $0.4-2.8$ & 0.816 \\
\hline Brain tumor $(n=7)$ & $4(57 \%)$ & 2.8 & $0.6-13.4$ & 0.220 & $3(43 \%)$ & 1.8 & $0.3-8.5$ & 0.427 \\
\hline NPC $(n=5)$ & $5(100 \%)$ & NA & NA & $0.003^{\mathrm{a}}$ & $3(60 \%)$ & 3.7 & $0.5-23.3$ & 0.159 \\
\hline $\operatorname{RMS}(n=6)$ & $1(17 \%)$ & 0.3 & $0.04-3.4$ & 0.662 & $3(50 \%)$ & 2.4 & $0.4-12.7$ & 0.363 \\
\hline Others $(n=2)$ & $1(50 \%)$ & 2.0 & $0.1-33.2$ & 1.000 & $1(50 \%)$ & 2.3 & $0.1-38.9$ & 0.512 \\
\hline \multicolumn{9}{|l|}{ RT field } \\
\hline Cervical $(n=25)$ & $6(24 \%)$ & 0.5 & $0.2-1.5$ & 0.343 & $7(28 \%)$ & 0.8 & $0.3-2.3$ & 1.000 \\
\hline Mantle $(n=4)$ & $3(75 \%)$ & 6.4 & $0.6-63.6$ & 0.107 & 0 & NA & NA & 0.315 \\
\hline Cranial $(n=9)$ & $5(56 \%)$ & 2.7 & $0.6-10.7$ & 0.158 & $2(22 \%)$ & 0.6 & $0.1-3.2$ & 0.722 \\
\hline Craniospinal $(n=3)$ & $1(33 \%)$ & 1.0 & $0.08-11.3$ & 1.000 & $1(33 \%)$ & 1.1 & $0.1-13.3$ & 1.000 \\
\hline Mediastinal $(n=6)$ & $2(33 \%)$ & 1.0 & $0.1-5.7$ & 1.000 & $1(17 \%)$ & 0.4 & $0.05-4.0$ & 0.667 \\
\hline Cervical + Naso-pharyngeal $(n=6)$ & $6(100 \%)$ & NA & NA & $0.001^{\mathrm{a}}$ & $3(50 \%)$ & 2.4 & $0.4-12.7$ & 0.363 \\
\hline Cervical + Media-stinal $(n=8)$ & & 1.2 & $0.2-5.3$ & 1.000 & $1(12 \%)$ & 0.3 & $0.03-2.6$ & 0.433 \\
\hline Head \& Neck (n=7) & & NA & NA & 0.094 & $5(71 \%)$ & 6.6 & $1.2-35.8$ & $0.025^{a}$ \\
\hline \multicolumn{9}{|l|}{ Dosage of RT (cGy) } \\
\hline$<2000(n=11)$ & $2(18 \%)$ & 0.4 & $0.08-2.0$ & 0.333 & 0 & NA & NA & $0.033^{\mathrm{a}}$ \\
\hline $2000-2999(n=28)$ & $13(46 \%)$ & 2.0 & $0.8-4.9$ & 0.111 & $8(29 \%)$ & 0.9 & $0.3-2.3$ & 1.000 \\
\hline $3000-3999(n=5)$ & 0 & NA & NA & 0.168 & $1(20 \%)$ & 0.5 & $0.06-5.2$ & 1.000 \\
\hline $4000-4999(n=7)$ & $1(14)$ & 0.3 & $0.03-2.7$ & 0.422 & $2(29 \%)$ & 0.9 & $0.1-5.0$ & 1.000 \\
\hline $5000-5999(n=7)$ & $4(57 \%)$ & 2.8 & $0.6-13.4$ & 0.220 & $5(71 \%)$ & 6.6 & $1.2-35.8$ & $0.025^{a}$ \\
\hline$\geq 6000(n=10)$ & $6(60 \%)$ & 3.3 & $0.8-12.6$ & 0.082 & $4(40)$ & 1.6 & $0.4-6.1$ & 0.485 \\
\hline \multicolumn{9}{|l|}{ ChT } \\
\hline Alkylating agents $(n=110)$ & $33(30 \%)$ & 0.1 & $0.04-0.7$ & $0.015^{\mathrm{a}}$ & $29(26 \%)$ & 0.1 & $0.03-0.6$ & $0.008^{\mathrm{a}}$ \\
\hline Antineoplastic antibiotics ( $n=102$ ) & $31(30 \%)$ & 0.4 & $0.1-1.2$ & 0.113 & $28(27 \%)$ & 0.4 & $0.1-1.3$ & 0.168 \\
\hline Antimetabolites $(n=65)$ & $21(32 \%)$ & 0.9 & $0.4-1.9$ & 0.847 & $22(34 \%)$ & 1.4 & $0.6-3.3$ & 0.424 \\
\hline Vinca alkaloids ( $n=116)$ & $36(31 \%)$ & NA & NA & $0.011^{\mathrm{a}}$ & $33(28 \%)$ & 0.1 & $0.01-1.3$ & 0.080 \\
\hline Steroids ( $n=106)$ & $32(30 \%)$ & 0.3 & $0.1-1.01$ & 0.068 & $29(27 \%)$ & 0.3 & $0.1-1.1$ & 0.118 \\
\hline Platinum derivatives $(n=9)$ & $7(78 \%)$ & 8.2 & $1.6-41.9$ & $0.006^{\mathrm{a}}$ & $6(67 \%)$ & 5.4 & $1.2-22.9$ & $0.021^{\mathrm{a}}$ \\
\hline Asparaginase ( $n=32$ ) & $12(37 \%)$ & 1.2 & $0.5-2.9$ & 0.662 & $9(28 \%)$ & 0.8 & $0.3-2.1$ & 0.826 \\
\hline Intrathecal $(n=60)$ & $16(27 \%)$ & 0.5 & $0.2-1.1$ & 0.175 & $19(32 \%)$ & 1.1 & $0.5-2.5$ & 0.842 \\
\hline Others $(n=11)$ & $3(27 \%)$ & 0.7 & $0.1-2.9$ & 0.750 & $6(54 \%)$ & 3.1 & $0.8-11.1$ & 0.084 \\
\hline
\end{tabular}


Akca Çağlar A et al.

Thyroid Abnormalities in Children with Cancer

\begin{tabular}{|c|c|c|c|c|c|c|}
\hline & Covariate & $e^{\beta}$ & $95 \%$ Cl & $\mathrm{p}$-value & Cox \& Snell R² & AUC \\
\hline HT & $\begin{array}{l}\text { HL } \\
\text { Brain tumor } \\
\text { NPC } \\
\text { Cervical RT } \\
\text { 5000-5999 cGy RT }\end{array}$ & $\begin{array}{l}23.508 \\
40.217 \\
598.766 \\
14.054 \\
40.217\end{array}$ & $\begin{array}{l}1.707-323.722 \\
1.716-942.577 \\
22.989-N A \\
2.807-70.375 \\
1.716-942.577\end{array}$ & $\begin{array}{l}0.018 \\
0.022 \\
0.000 \\
0.001 \\
0.022\end{array}$ & 0.486 & 0.696 \\
\hline Nodules & $\begin{array}{l}\text { HL } \\
4000-4999 \text { cGy RT } \\
5000-5999 \text { cGy RT }\end{array}$ & $\begin{array}{l}10.307 \\
15.397 \\
23.478\end{array}$ & $\begin{array}{l}3.141-33.823 \\
2.079-114.012 \\
3.822-144.220\end{array}$ & $\begin{array}{l}0.000 \\
0.007 \\
0.001\end{array}$ & 0.236 & 0.671 \\
\hline $\begin{array}{l}\text { Autoimmune } \\
\text { thyroiditis }\end{array}$ & $\begin{array}{l}\text { Head \& Neck RT } \\
\text { Platinum derivatives }\end{array}$ & $\begin{array}{l}6.490 \\
5.312\end{array}$ & $\begin{array}{l}1.160-36.325 \\
1.214-23.237\end{array}$ & $\begin{array}{l}0.033 \\
0.027\end{array}$ & 0.085 & 0.728 \\
\hline
\end{tabular}

HT will usually occur within the first 5 years of treatment, with the peak occurring 2-3 years after the therapy. However, occurrences as late as 20 years and as early as within 3 months after the completion of therapy, were also reported $(15,16)$. Our results showed a median interval of 5 years between completion of therapy and occurrence of $\mathrm{HT}$.

Recent studies showed that female sex and younger age at diagnosis of malignancy are independent risk factors for $\mathrm{HT}$ in irradiated patients $(4,10,13,15,17,18,19)$. However, we found no significant relationship between gender, age at diagnosis of malignancy and evidence of any thyroid disorder, except for autoimmune thyroiditis, which was more common in girls.

In patients with $\mathrm{HL}$, the reported incidence of primary HT vary from $25 \%$ to $88 \%(4,12,15,19,20,21,22,23)$. In our study, the incidence of primary HT among the $43 \mathrm{HL}$ patients was $51 \%$ (22 patients). Radiation therapy to the neck is a well-known risk factor for subsequent thyroid disease $(12,13,15,18,24,25)$. A recent study by Bhatia et al (21) reported mantle irradiation with an estimated relative risk of 9.9 for the development of HT. In our series, we found that cervical, mantle and cervical + nasopharyngeal irradiation were all risk factors leading to $\mathrm{HT}$.

The risk of $\mathrm{HT}$ is greatest after therapy for $\mathrm{HL}$ where $\mathrm{RT} 3500-$ 4500 cGy is often used $(13,15,25)$. In our study, we found an elevated risk for $\mathrm{HT}$ in patients with $\mathrm{HL}$ treated with doses of 2000-2999 cGy as well as in patients with brain tumor, NPC and RMS treated with $\geq 5000 \mathrm{cGy}$ doses of radiation.

In children with brain tumor, primary $\mathrm{HT}$ is more prevalent than central HT. Paulino et al (17) documented primary HT in 38\% and central HT in $19 \%$ of patients with brain tumor. Our study confirms previous reports indicating that prevalence of primary $\mathrm{HT}$ was greater than central $\mathrm{HT}$ in patients with brain tumor. This reflects the fact that the thyroid gland may receive some degree of radiation scatter in the course of cranial and spinal RT.

The effects of RT on the thyroid gland are well documented in survivors of childhood cancer. However, the side effects of ChT on thyroid function are still being debated. Chemotherapeutic agents were found to be associated with an increased risk of thyroid dysfunction in several studies $(3,10,15,16,17,25,26,27,28,29)$, while other studies reported no such results $(4,5,11,12,13$, $14,20,21,22,24,30,31,32,33,34,35,36,37,38)$. In our study, chemotherapeutic agents were not found to increase the incidence of $\mathrm{HT}$.

It has also been shown that RT involving the head and neck, particularly when applied during childhood, increases the risk of developing subsequent benign or malignant thyroid masses (4). Solt et al (36) reported an incidence of $54 \%$ of morphological abnormalities of thyroid gland detected by ultrasonography among $\mathrm{HL}$ patients who underwent mantle irradiation. Soberman et al (39) reported ultrasound-detected abnormalities in $89 \%$ of 18 long-term survivors of $\mathrm{HL}$ at a mean time interval of 6.4 years. In our series, thyroid nodules were seen in 27 of 120 survivors $(22 \%)$ at a median interval of 9 years after the therapy and the frequency of ultrasound-detected thyroid nodules was significantly higher among patients treated with combination therapy than in those who had received ChT alone. We found a significant association of thyroid nodules with a history of $\mathrm{HL}$ and mantle irradiation.

A dose-response relationship between radiation exposure to the thyroid and thyroid nodules was reported in one study in which survivors who received an estimated dose of 15-30 Gy to the thyroid gland were 6.0 times and those who received estimated dose of 31-66 Gy to the thyroid gland were 8.2 times more likely to develop nodules than patients receiving an estimated dose of $<2 \mathrm{~Gy}$ to the thyroid gland (40). We also found that treatment with 4000-5999 cGy doses of radiation were associated with increased risk of developing thyroid nodules.

Some recent studies reported abnormalities detected by ultrasonography in the thyroid gland after RT $(40,41)$ and several studies showed that RT can induce autoimmune thyroiditis $(12,25)$. Tamura et al $(25)$ reported that the incidence of $A B$ positivity was less frequent in patients who had also received 
ChT than in patients who had received RT only, so they proposed that $\mathrm{ChT}$, through its immunosuppressive effect, might control autoimmune thyroiditis induced by irradiation. In our study however, patients who were treated with combination therapy had a similar incidence of thyroid parenchymal heterogeneity and autoimmune thyroiditis as patients treated with ChT only. The incidence of autoimmune thyroiditis in two of our patient groups was found to be higher than that reported in Turkish children (42). Our study is the first to describe thyroid parenchymal heterogeneity and autoimmune thyroiditis in patients treated during childhood with ChT only. As autoimmune disorders tend to be transformed in lymphoproliferative diseases (43), this result may be due to either the disease itself or to the effect of ChT.

Thyroid parenchymal heterogeneity and autoimmune thyroiditis were significantly associated with treatment with platinum derivatives. Although seven of nine children treated with platinum derivatives also received $\mathrm{RT}$, we suggest that the toxic effects of ChT may be independent of those of RT.

In conclusion, our results indicate an increased risk of $\mathrm{HT}$ and thyroid nodules in patients treated with combination therapy of ChT with head/neck/thorax RT. Chemotherapeutic agents do not seem to cause HT as an adverse late effect. In view of the similar frequency of autoimmune thyroiditis and thyroid parenchymal heterogeneity between patients treated with ChT only and combination therapy, longer follow-up is needed to assess whether or not there is an increased risk for these abnormalities after antineoplastic therapy.

\section{References}

1. Bhatia S. Cancer survivorship-pediatric issues. Hematology Am Soc Hematol Educ Program 2005:507-515.

2. Sklar CA. Overview of the effects of cancer therapies. Acta Paediatr Suppl 1999;88:1-4.

3. Ogilvy-Stuart AL, Shalet SM, Gattamaneni HR. Thyroid function after treatment of brain tumors in children. J Pediatr 1991;119:733-737.

4. Sklar C, Whitton J, Mertens A, Stovall M, Green D, Marina N, Greffe B, Wolden S, Robison L. Abnormalities of the thyroid in survivors of Hodgkin's disease: data from the Childhood Cancer Survivor Study. J Clin Endocrinol Metab 2000;85:3227-3232.

5. Chow EJ, Friedman DL, Stovall M, Yasui Y, Whitton JA, Robison LL, Sklar CA. Risk of thyroid dysfunction and subsequent thyroid cancer among survivors of acute lymphoblastic leukemia: a report from the Childhood Cancer Survivor Study. Pediatr Blood Cancer 2009;53:432-437.

6. Marcus KJ, Haas-Kogan D. Pediatric radiation oncology. In: Orkin SH, Fisher DE, Look AT, Lux SE, Ginsburg D, Nathan DG (eds). Oncology of Infancy and Childhood. Philadelphia, Saunders Elsevier, 2009:241-256.

7. Jereczek-Fossa BA, Alterio D, Jassem J, Gibelli B, Tradati N, Orecchia R. Radiotherapy-induced thyroid disorders. Cancer Treat Rev 2004;30:369-384.

8. Hancock SL, McDougall IR, Constine LS. Thyroid abnormalities after therapeutic external radiation. Int J Radiat Oncol Biol Phys 1995;31:1165-1170.

9. Kaplan EL, Meier P. Nonparametric estimation from incomplete observations. J Am Stat Assoc 1958;53:457-481.
10. Madanat LM, Lähteenmäki PM, Alin J, Salmi TT. The natural history of thyroid function abnormalities after treatment for childhood cancer. Eur J Cancer 2007;43:1161-1170. Epub 2007 Mar 27

11. van Santen HM, Vulsma T, Dijkgraaf MG, Blumer RM, Heinen $R$, Jaspers MW, Geenen MM, Offringa MO, de Vijlder JJ, van den Bos C. No damaging effect of chemotherapy in addition to radiotherapy on the thyroid axis in young adult survivors of childhood cancer. J Clin Endocrinol Metab 2003;88:3657-3663.

12. Illés $A$, Bíró $E$, Miltényi $Z$, Keresztes $K$, Váróczy $L$, András $C$, Sipka S, Bakó G. Hypothyroidism and thyroiditis after therapy for Hodgkin's disease. Acta Haematol 2003;109:11-17.

13. Schimpff SC, Diggs CH, Wiswell JG, Salvatore PC, Wiernik $\mathrm{PH}$. Radiation related thyroid dysfunction: implications for the treatment of Hodgkin's disease. Ann Intern Med 1980;92:9198.

14. Schmiegelow M, Feldt-Rasmussen U, Rasmussen AK, Poulsen HS, Müller J. A population-based study of thyroid function after radiotherapy and chemotherapy for a childhood brain tumor. $J$ Clin Endocrinol Metab 2003;88:136-140.

15. Hancock SL, Cox RS, McDougall IR. Thyroid diseases after treatment of Hodgkin's disease. N Engl J Med 1991;325:599605.

16. Cutuli B, Quentin P, Rodier JF, Barakat P, Grob JC. Severe hypothyroidism after chemotherapy and locoregional irradiation for breast cancer. Radiother Oncol 2000;57:103-105.

17. Paulino AC. Hypothyroidism in children with medulloblastoma: a comparison of 3600 and 2340 cGy craniospinal radiotherapy. Int J Radiat Oncol Biol Phys 2002;53:543-547.

18. Khoo VS, Liew KH, Crennan EC, D'Costa IM, Quong G. Thyroid dysfunction after mantle irradiation of Hodgkin's disease patients. Australas Radiol 1998;42:52-57.

19. Green DM, Brecher ML, Yakar D, Blumenson LE, Lindsay AN, Voorhess ML, MacGillivray M, Freeman Al. Thyroid function in pediatric patients after neck irradiation for Hodgkin disease. Med Pediatr Oncol 1980;8:127-136.

20. Devney RB, Sklar CA, Nesbit ME Jr, Kim TH, Williamson JF, Robison LL, Ramsay NK. Serial thyroid function measurements in children with Hodgkin disease. J Pediatr 1984;105:223-227.

21. Bhatia S, Ramsay NK, Bantle JP, Mertens A, Robison LL. Thyroid Abnormalities after Therapy for Hodgkin's Disease in Childhood. Oncologist 1996;1:62-67.

22. Metzger ML, Hudson MM, Somes GW, Shorr RI, Li CS, Krasin MJ, Shelso J, Pui CH, Howard SC. White race as a risk factor for hypothyroidism after treatment for pediatric Hodgkin's lymphoma. J Clin Oncol 2006;24:1516-1521.

23. Shalet SM, Rosenstock JD, Beardwell CG, Pearson D, Jones PH. Thyroid dysfunction following external irradiation to the neck for Hodgkin's disease in childhood. Clin Radiol 1977;28:511-515.

24. Smith RE Jr, Adler AR, Clark P, Brinck-Johnsen T, Tulloh ME, Colton T. Thyroid function after mantle irradiation in Hodgkin's disease. JAMA 1981;245:46-49.

25. Tamura K, Shimaoka K, Friedman M. Thyroid abnormalities associated with treatment of malignant lymphoma. Cancer 1981:47:2704-2711

26. Livesey EA, Brook CG. Thyroid dysfunction after radiotherapy and chemotherapy of brain tumours. Arch Dis Child. 1989;64:593595.

27. Rose SR, Schreiber RE, Kearney NS, Lustig RH, Danish RK, Burghen GA, Hudson MM. Hypothalamic dysfunction after chemotherapy. J Pediatr Endocrinol Metab 2004;17:55-66.

28. Paulides M, Dörr HG, Stöhr W, Bielack S, Koscielniak E, Klingebiel T, Jürgens $H$, Bölling T, Willich N, Sauer R, Langer T, Beck JD;Late Effects Surveillance System. Thyroid function 
Akca Çağlar A et al.

Thyroid Abnormalities in Children with Cancer

in paediatric and young adult patients after sarcoma therapy: a report from the Late Effects Surveillance System. Clin Endocrinol (Oxf) 2007;66:727-731. Epub 2007 Mar 23

29. Stuart NS, Woodroffe CM, Grundy R, Cullen MH. Long-term toxicity of chemotherapy for testicular cancer-the cost of cure. Br J Cancer 1990;61:479-484.

30. Mercado G, Adelstein DJ, Saxton JP, Secic M, Larto MA, Lavertu P. Hypothyroidism: a frequent event after radiotherapy and after radiotherapy with chemotherapy for patients with head and neck carcinoma. Cancer 2001;92:2892-2897.

31. Metzger ML, Howard SC, Hudson MM, Gow KW, Li CS, Krasin MJ, Merchant T, Kun L, Shelso J, Pui CH, Shochat SJ, McCarville MB. Natural history of thyroid nodules in survivors of pediatric Hodgkin lymphoma. Pediatr Blood Cancer 2006;46:314-319.

32. Nygaard R, Bjerve KS, Kolmannskog S, Moe PJ, Wesenberg F Thyroid function in children after cytostatic treatment for acute leukemia. Pediatr Hematol Oncol 1988;5:35-38.

33. Chin D, Sklar C, Donahue B, Uli N, Geneiser N, Allen J, Nirenberg A, David R, Kohn B, Oberfield SE. Thyroid dysfunction as a late effect in survivors of pediatric medulloblastoma/primitive neuroectodermal tumors: a comparison of hyperfractionated versus conventional radiotherapy. Cancer 1997;80:798-804.

34. Heikens J, Michiels EM, Behrendt H, Endert E, Bakker PJ, Fliers E. Long term neuro-endocrine sequelae after treatment for childhood medulloblastoma. Eur J Cancer 1998;34:1592-1597.

35. van Beek RD, van den Heuvel-Eibrink MM, Hakvoort-Cammel $F G$, van den Bos $C$, van der Pal HJ, Krenning EP, de Rijke $Y B$, Pieters R, de Muinck Keizer-Schrama SM. Bone mineral density, growth, and thyroid function in long-term survivors of pediatric Hodgkin's lymphoma treated with chemotherapy only. J Clin Endocrinol Metab 2009;94:1904-1909. Epub 2009 Mar 17
36. Solt I, Gaitini D, Pery M, Hochberg Z, Stein M, Arush MW Comparing thyroid ultrasonography to thyroid function in longterm survivors of childhood lymphoma. Med Pediatr Oncol 2000;35:35-40.

37. Schmiegelow M, Feldt-Rasmussen $U$, Rasmussen AK, Lange M, Poulsen HS, Müller J. Assessment of the hypothalamopituitary-adrenal axis in patients treated with radiotherapy and chemotherapy for childhood brain tumor. J Clin Endocrinol Metab 2003;88:3149-3154.

38. Madanat LM, Lähteenmäki PM, Hurme S, Dyba T, Salmi TT, Sankila R. Hypothyroidism among pediatric cancer patients: a nationwide, registrybased study. Int J Cancer 2008;122:1868-1872.

39. Soberman N, Leonidas JC, Cherrick I, Schiff R, Karayalcin G. Sonographic abnormalities of the thyroid gland in long term survivors of Hodgkin disease. Pediatr Radiol 1991;21:250-253.

40. Crom DB, Kaste SC, Tubergen DG, Greenwald CA, Sharp GB, Hudson MM. Ultrasonography for thyroid screening after head and neck irradiation in childhood cancer survivors. Med Pediatr Oncol 1997;28:15-21.

41. Buba a H, G owacki J, Legaszewski T, So ta-Jakimczyk D, Janik-Moszant A, Szczepa ski T. Ultrasonographic evaluation of thyroid in patients cured from Hodgkin disease. Wiad Lek 1998;51(Suppl 4):186-192.

42. Doğan M, Acikgoz E, Acikgoz M, Cesur Y, Ariyuca S, Bektas MS. The frequency of Hashimoto thyroiditis in children and the relationship between urinary iodine level and Hashimoto thyroiditis. J Pediatr Endocrinol Metab 2011;24:75-80.

43. Váróczy L, Gergely L, Zeher M, Szegedi G, Illés A. Malignant lymphoma associated autoimmune diseases-a descriptive epidemiological study. Rheumatol Int 2002;22:233-237. Epub 2002 Aug 29 